\title{
A arqueologia e seus limites ${ }^{1}$
}

\author{
Archeology and its limits
}

\section{Monica Loyola Stival ${ }^{*}$}

Universidade Federal de São Carlos (UFSCar), São Carlos, SP, Brasil

\section{Resumo}

Trata-se de mostrar os limites da noção de arqueologia, considerando particularmente o livro A arqueologia do saber, que Foucault publica em 1969. A questão é o estatuto da síntese que delimita uma formação discursiva e, mais do que isso, o sentido do vínculo que desenha o espaço quase-transcendental de uma episteme, considerando não tanto a descontinuidade que a separa de outra episteme, mas a espessura que lhe fornece um sentido próprio. Com efeito, o artigo procura mostrar o inconveniente de uma arqueologia (como em Alain de Libera), sugerindo que outras perspectivas metodológicas, como a própria genealogia, permitiriam efetivamente descrever uma rede de acontecimentos, relançada em sua contingência radical.

Palavras-chave: Arqueologia. Foucault.

1 Este artigo é parte dos resultados de pesquisa financiada pelo CNPq - Conselho Nacional de Desenvolvimento Científico e Tecnológico.

"MLS: Doutora em Filosofia, e-mail: stivalmonica@gmail.com 


\section{Abstract}

The claim of this article is showing the limits of the notion of archeology, especially considering the book The archeology of knowledge, published by Foucault in 1969. The question is the statute of the synthesis that delimits a discursive formation and, more than that, the sense of the bond which draws the quasi-transcendental space of an episteme, considering not so much the discontinuity that separates it from another episteme, but the thickness that gives it a proper meaning. In fact, the article seeks to show the inconvenience of archeology (as in Alain de Libera), suggesting that other methodological perspectives, such as genealogy itself, would effectively describe a network of events relaunched in its radical contingency.

Keywords: Archeology. Foucault.

“Toda fronteira é porosa. Todo acontecimento (événement) esconde um processo" ${ }^{\prime 2}$. Uma vez que toda fronteira arqueológica seria incerta, ou pelo menos aberta, por que encerrar o processo em uma fronteira? A combinação entre uma "diversidade rebelde" e uma "estrutura", que permite a Alain de Libera situar a questão da arqueologia em sua aula inaugural no Collège de France $^{3}$, parece mostrar que uma arqueologia depende, via de regra, dessa espécie de oximoro. Não seria o caso de passar diretamente à porosidade, que tem como sentido último a dissolução das fronteiras - ou pelo menos a junção destas em redes sutis? ${ }^{4}$

O termo "arqueologia" tornou-se bastante usual desde que Foucault o lançou ao centro de uma filosofia capaz de repensar a noção de "história", continuísta ou dialética. Quando escreve uma arqueologia

2 Libera, Où va la philosophie médiévale?, parágrafo 10.

3 Libera, Où va la philosophie médiévale?, 13 de fevereiro de 2014.

4 "Nossas pobres redes são como os curdos anexados pelos iranianos, iraquianos e turcos que, uma vez caída a noite, atravessam as fronteiras, casam-se entre eles e sonham com uma pátria comum a ser extraída dos três países que os desmembram" (Latour, 1994, p. 12). Parece possível reencontrar espaços de relações que não se subtraem a perspectivas críticas cujas fronteiras definem cortes que desatam o que não se poderia, talvez, desatar. Esta perspectiva, que atravessa as fronteiras das quais uma arqueologia depende, é discutida em artigo complementar, intitulado "Da arqueologia às redes". 
das ciências humanas, Foucault encontra (ou constrói?) fronteiras que circunscrevem epistemes específicas, que circunscrevem algo que adquire certa unidade, uma episteme que difere da episteme que a antecede e da que a sucede. Essas espessuras são certas continuidades específicas em uma história descontínua. Seus limites são incertos e precisam de certa distância para serem percebidos - é como olhar um quadro impressionista. $\mathrm{O}$ arqueólogo, a certa distância, pode não reconhecer exatamente o traço que rompe em epistemes a história do saber, já que ele nem mesmo existe, mas pode descrever com precisão certos elementos, épocas, racionalidades distintas.

A possibilidade dessa síntese, dessa espessura, provocando um regime de verdade no campo dos enunciados e, com isso, no modo de ser, não é nunca muito diferente de um pressuposto crítico. Portanto, a questão aqui é mostrar que o problema filosófico interessante - para refletir sobre a arqueologia - está na síntese que, para Foucault, circunscreve uma formação discursiva, ou algumas formações discursivas. A partir desse problema é possível mostrar os limites de uma arqueologia - as fronteiras que ela pretende descrever são arbitrárias e a espessura que dois limites marcam no tempo é uma região problemática. Daí se segue o limite da arqueologia como perspectiva metodológica. As fronteiras da crítica, na reflexão sobre as ciências, são simulacros de uma síntese pressuposta ou imposta.

\section{I- Atomismo: as unidades do discurso}

"Seria natural esperar que eu acrescentasse a diferença às demais relações. Mas considero esta antes a negação de uma relação que algo real e positivo" ${ }^{\prime \prime}$.

(David Hume, Tratado da Natureza Humana).

Como se constituem as "individualidades históricas"? A singularidade dos acontecimentos, a singularidade dos enunciados, não é

5 Hume, Tratado da Natureza Humana, I, I, V. 
certamente vivida como descontinuidade. Por isso é preciso, segundo Foucault, "numa primeira aproximação, aceitar um recorte provisório: uma região inicial que a análise revolucionará e reorganizará se houver necessidade ${ }^{\prime \prime}$. Parte-se de uma complexidade que empiricamente aparece na forma de um evento entre outros, um enunciado de alguma maneira ligado a outros. Certamente, esse ponto de partida - um evento, um acontecimento, um objeto - já está distante de uma causalidade banal, que há muito se mostrou uma inferência perigosa. Muitas vezes ele aparece no arranjo frágil de um título abstrato, como "ciência".

É porque, na experiência, os acontecimentos e enunciados nascem em relações (como aquelas que compõem um livro, uma obra, ou que afirmam uma influência) que é preciso partir da recusa de relações que se oferecem à inteligibilidade imediata do enunciado. A "descrição dos acontecimentos discursivos" é sobretudo uma reordenação possível de relações habitualmente dadas.

É preciso pôr em questão, novamente, essas sínteses acabadas, esses agrupamentos que, na maioria das vezes, são aceitos antes de qualquer exame, esses laços cuja validade é reconhecida desde o início; é preciso desalojar essas formas e essas forças obscuras pelas quais se tem o hábito de interligar os discursos dos homens; é preciso expulsá-las da sombra onde reinam? ${ }^{7}$.

Colocar em questão as sínteses habituais não significa simplesmente evitar a nomeação de uma unidade arbitrária, mas significa rever e por vezes recusar a unidade nominal que organiza a experiência dos acontecimentos discursivos. $\mathrm{O}$ trabalho negativo da arqueologia permite instituir diferenças, negando relações pressupostas, de modo a "restituir ao enunciado sua singularidade de acontecimento" ${ }^{8}$. Abre-se espaço assim a outras formas de regularidade e à descrição consciente de novas sínteses.

6 Foucault, $A$ arqueologia do saber, p. 33; fr. p. 45.

7 Foucault, A arqueologia do saber, p. 24; fr. p. 34.

8 Foucault, A arqueologia do saber, p. 21; fr. p. 43. 
O método arqueológico pode chegar assim à descrição de acontecimentos discursivos singulares como elementos de uma ontologia histórica indireta ${ }^{9}$. A dificuldade da arqueologia não está nessa tarefa negativa, mas no estatuto das sínteses encontradas ou construídas ao final do processo, por mais que se apresentem como possibilidades dentro de um vasto campo de composição e reordenação possível: uma arqueologia.

Porém, é preciso notar que mesmo a análise capaz de destacar unidades a partir da negação de relações aparentes ou habituais pode ser um caminho sem volta, uma "purificação" cuja instauração perde para sempre o sentido que as redes empiricamente dadas trazem consigo. Uma vez que a diferença é posta, a associação que reconfigura redes de enunciados tem sempre o perigo da (re)constituição arbitrária.

\section{II - Associacionismo: as regras de formação de um discurso}

Se Foucault procura reordenar de maneira relativamente livre os elementos simples de uma formação histórica fornecida geralmente pelo hábito - como "ciência" ou "a medicina", "a economia", "a gramática" -, ele não deixa de remeter as unidades do discurso a certas condições de existência. A reordenação é livre no sentido de que ela é fruto de uma análise situada em "um espaço branco, indiferente, sem interioridade nem promessa"10. Porém, esse espaço é aquele em que se pode surpreender alguma "regularidade"11, de modo que a

9 Apesar de ser definido por Foucault como uma função, 0 enunciado está sempre em relação com um campo associado e, nessa medida, falo em ontologia indireta. Ele lida com uma função enunciativa "pondo em jogo unidades diversas (elas podem coincidir às vezes com frase, às vezes com proposições ; mas são feitas às vezes de fragmentos de frases, séries ou quadros de signos, jogo de proposições ou formulações equivalentes) ; e essa função, em vez de dar um 'sentido' a essas unidades, coloca-as em relação com um campo de objetos; em vez de lhes conferir um sujeito, abre-lhes um conjunto de posições subjetivas possíveis; em vez de Ihes fixar limites, coloca-as em domínio de coordenação e de coexistência; em vez de Ihes determinar a identidade, aloja-as em um espaço em que são consideradas, utilizadas e repetidas." (FOUCAULT, $A$ arqueologia do saber, p. 120; fr. p. 146).

${ }_{10}$ Foucault, A arqueologia do saber, p. 44; fr. p. 58.

11 "No caso em que se puder descrever entre um certo número de enunciados, semelhante sistema de dispersão, e no caso em que entre os objetos, os tipos de enunciação, os conceitos, as escolhas temáticas, se puder definir uma regularidade (uma

Rev. Filos., Aurora, Curitiba, v. 31, n. 52, p. 278-303, jan./abr. 2019 
formação discursiva não é aleatória. Mas, ao definir-se em uma decisão interpretativa que tem diante de si unidades discursivas, o espaço de uma formação específica traz mais à cena, no texto de Foucault, do que um fluxo regular de singularidades. Ele as remete a condições, ainda que o conceito de "formações discursivas" quisesse evitá-las. "As regras de formação são condições de existência (mas também de coexistência, de manutenção, de modificação e de desaparecimento) em uma repartição discursiva" 12 .

De que ordem seriam tais condições? A análise de uma formação discursiva revela "um conjunto de regras que são imanentes a uma prática e a definem em sua especificidade" ${ }^{13}$. As regras são então próprias do feixe de relações ${ }^{14}$ que compõe uma formação discursiva, e não são ontológicas, da ordem das coisas, nem linguísticas, da ordem das palavras. Trata-se de uma gramática específica dos objetos discursivos. Até aí, a arqueologia guarda a contingência empírica (prática) de sua formação, em acordo com o que Foucault chamará mais tarde de "nominalismo em história" ou, em formulação similar, de "genealogia". Trata-se, afinal, da emergência ou aparição do "objeto de discurso". A existência do objeto em jogo é discursiva ${ }^{15}$ e sua genealogia constitui-se na própria descrição interpretativa das unidades do discurso: "seria preciso incialmente demarcar as superfícies primeiras de sua emergência"16. Porém, a questão arqueológica não está tanto na descrição do espaço de emergência dos objetos (a formação dos objetos), o que a genealogia fará mais exatamente, mas no conjunto de regras que constituem tais objetos em uma relação a um só tempo de coexistência

ordem, correlações, posições e funcionamentos, transformações), diremos, por convenção, que se trata de uma formação discursiva" (FOUCAULT, A arqueologia do saber, p. 43, fr. p. 56).

12 Foucault, $A$ arqueologia do saber, p. 43; fr. p. 56.

${ }^{13}$ Foucault, $A$ arqueologia do saber, p. 52; fr. p. 68.

14 As relações discursivas "determinam o feixe de relações que o discurso deve efetuar para poder falar que tais ou tais objetos, para poder abordá-los, nomeá-los, analisá-los, classificá-los, explicá-los etc." (FOUCAULT, A arqueologia do saber, p. 52; fr. p. 67).

15 "Nesses campos de diferenciação primeira, nas distâncias, descontinuidades e limiares que então se manifesta, 0 discurso psiquiátrico encontra a possibilidade de limitar seu domínio, de definir aquilo de que fala, de dar-lhe status de objeto - ou seja, de fazê-lo aparecer, de torna-lo nomeável e descritível" (FOUCAULT, A arqueologia do saber, p. 47; fr. p. 61).

16 Foucault, A arqueologia do saber, p. 46; fr. p. 60. 
e dispersão. É nesse plano que a questão das condições de existência se coloca.

Objetos de discurso não são equivalentes, portanto, a uma formação discursiva, cujas regras imanentes são o espaço de formação daqueles objetos ${ }^{17}$. O problema se repete para as "modalidades enunciativas", no sentido de que elas compõem uma formação discursiva mas não envolvem ainda o quadro mais amplo que uma arqueologia delimita. O discurso clínico, por exemplo, tem sua unidade circunscrita por um "feixe de relações", e Foucault pretende evitar assim uma síntese dos diferentes planos que lhe concernem por uma estrutura formal transcendental ou por um referente psicológico ${ }^{18}$. "Se esses planos estão ligados por um sistema de relações, este não é estabelecido pela atividade sintética de uma consciência idêntica a si, muda e anterior a qualquer palavra, mas pela especificidade de uma prática discursiva" ${ }^{\prime 19}$.

É como um tipo específico de fluência de vividos em uma cultura que se destaca uma disciplina tal como o discurso clínico, numa unidade incerta e como campo de exterioridade (objetos que distinguem um discurso participam do mesmo campo de saber): "se tem uma unidade, se as modalidades de enunciação que utiliza, ou às quais dá lugar, não são simplesmente justapostas por uma série de contingências histórias, é porque emprega, de forma constante, esse feixe de relações" ${ }^{20}$. Tratase então de constância em um feixe de relações que são exteriores aos objetos e que não são condições formais estruturantes.

17 "No caso em que se puder descrever, entre um certo número de enunciados, semelhantes sistema de dispersão, e no caso em que entre os objetos, os tipos de enunciação, os conceitos, as escolhas temáticas, se puder definir uma regularidade (uma ordem, correlações, posições e funcionamentos, transformações), diremos, por convenção, que se trata de uma formação discursiva" (FOUCAULT, A arqueologia do saber, p. 43; fr. p. 56).

${ }^{18}$ Estamos, como em Hume, no campo prático, distantes de um sujeito transcendental de tipo kantiano e de alguma consciência aos moldes de Locke ou Descartes. "Ter reduzido o ego a uma fluência de vividos, a transições de percepções, foi um dos lances de gênio de Hume" (Lebrun, David Hume dans l'album de famille husserlien, p. 51). No que diz respeito ao estatuto da síntese de um discurso (conjunto de enunciados) ou de uma "consciência" (conjuntos de vividos), assim como o discurso clínico, em Foucault, para Hume a mente "não é senão um feixe ou coleção de diferentes percepções, unidas por certas relações, e as quais supomos, embora falsamente, serem dotadas de uma perfeita simplicidade e identidade" (Hume, Tratado da Natureza Humana, I, IV, II, p. 240).

19 Foucault, A arqueologia do saber, p. 61; fr. p. 78.

20 Foucault, A arqueologia do saber, p. 60; fr. p. 83.

Rev. Filos., Aurora, Curitiba, v. 31, n. 52, p. 278-303, jan./abr. 2019 
A formação dos conceitos de um discurso envolve sucessão, coexistência e procedimentos de intervenção. De modo geral, é novamente um "feixe de relações que constitui um sistema de formação conceitual" 21 , porque aqueles elementos funcionam como baliza de análise para este feixe de relações no que diz respeito à formação dos conceitos. É a maneira como aqueles elementos se apresentam (a maneira como eles se constituem) que fornece o solo da síntese discursiva neste plano, isto é, no nível de uma individualidade histórica específica (o discurso clínico, a gramática, a história geral, etc.): “o que pertence propriamente a uma formação discursiva e o que permite delimitar o grupo de conceitos, embora discordantes, que lhe são específicos, é a maneira pela qual esses diferentes elementos estão relacionados uns aos outros" 22 .

Assim, a unidade de um discurso é relativa à rede de conceitos, objetos e relações que se articulam na prática discursiva, formando um campo articulado e, ao mesmo tempo, constituído em uma dispersão conceitual. Essa dispersão não é problemática na medida em que os conceitos são termos de construção interna que obedecem a diferentes formas de relações, exteriores àqueles. Assim, a arqueologia pretende instalar-se em um campo "pré-conceitual" que "não remete nem a um horizonte de idealidade nem a uma gênese empírica das abstrações" ${ }^{23}$. Estamos, ao que parece, no plano prático dos vividos de um discurso - não, certamente, na forma de um sujeito, mas, ao invés deste, na forma discursiva. Isso porque Foucault inverte a primazia do sujeito das filosofias que o precederam em primazia do discurso. Afinal, sobre esse campo "pré-conceitual": “o sistema, perfeitamente descritível, por ele constituído, dá conta de um jogo considerável de conceitos e de um número muito importante de transformações que afetam, ao mesmo tempo, esses conceitos e suas relações" ${ }^{24}$. Como observa Canguilhem, a arqueologia é "a condição de uma outra história, na qual o conceito

\footnotetext{
21 Foucault, A arqueologia do saber, p. 66; fr. p. 83

22 Foucault, $A$ arqueologia do saber, p. 65; fr. p. 83.

23 Foucault, A arqueologia do saber, p. 68; fr. p. 86.

24 Foucault, A arqueologia do saber, p. 69; fr. p. 87.
} 
de acontecimento é conservado, mas onde os acontecimentos afetam conceitos e não homens" 25 .

Embora uma questão embaraçosa se imponha (o que significa certa afecção na ordem dos conceitos?), as linhas gerais de uma análise do discurso estão traçadas de modo a dar contornos a um plano de análise interessante, no qual a arqueologia pretende se situar. Até aqui tudo vai bem. Com o mérito de assegurar a contingência, a formação e a singularidade dos objetos, conceitos e modalidades enunciativas que circunscrevem uma formação discursiva, Foucault põe em jogo um campo em que a síntese é a cada vez um horizonte problemático. Porém, mais incerta do que a noção de "feixe de relações" é a analogia que sustenta a ligação entre diferentes discursos ou individualidades históricas. Por exemplo, a analogia que liga formações discursivas clássicas, descritas em As palavras e as coisas, de 1966. No que diz respeito à gramática geral, à história natural e à análise das riquezas, "esses conjuntos de regras são bastantes específicos, em cada um desses domínios, para caracterizar uma formação discursiva singular e bem individualizada; mas apresentam analogias suficientes para que vejamos essas diversas formações constituírem um grupamento discursivo mais vasto e de um nível mais elevado" 26 .

Aquelas individualidades históricas - mesmo que analisadas em uma periodização que destaque o que pode haver de próprio, por exemplo na história natural, na sua idade clássica - são descritas ou analisadas segundo balizas metodológicas que não são estranhas à genealogia e que, aliás, exemplificam muito exatamente o que Foucault chamará, com certa liberdade poética, de "nominalismo em história". Entretanto, as analogias que vinculariam essas individualidades assumem-se, aos poucos, enquanto condições formais de existência, regime de uma forma específica de verdade. Como se sabe, "em Les mots et les choses o estudo se referia, em sua parte principal, às redes de conceitos e suas regras de formação (idênticas ou diferentes), tais como podiam ser demarcadas na gramática geral, na história natural e na análise das

25 Canguilhem, Mort de l'homme ou épuisement du Cogito?, p. 260.

${ }^{26}$ Foucault, A arqueologia do saber, p. 69; fr. p. 88.

Rev. Filos., Aurora, Curitiba, v. 31, n. 52, p. 278-303, jan./abr. 2019 
riquezas" 27 . A questão é justamente como certas regras de formação ou redes de conceitos atravessam formações discursivas singulares e, mais que isso, delimitam a especificidade de um período em relação a diferentes discursos.

Sobre o primeiro ponto, tudo segue ainda uma ordenação prática específica, conforme um método que fosse genealógico de análise de um discurso. Há objetos, enunciados ou conceitos que são possíveis em uma formação discursiva segundo determinado nível, mas impossíveis - ou pelo menos são excluídos - em função da constelação mais ampla na qual se inserem, que coloca aquele nível em relação (analogia, oposição ou complementaridade) com outros níveis de formação. Segundo Foucault, em um determinado discurso, "há sistematizações conceituais, encadeamentos enunciativos, grupos e organizações de objetos que teriam sido possíveis (e cuja ausência não pode ser justificada no nível de suas regras próprias de formação), mas que são excluídos por uma constelação discursiva de um nível mais elevado e de maior extensão" 28 .

Ou seja, há uma hierarquia em relação a tudo o que compõe um discurso como, por exemplo, a História natural. "Os níveis não são, pois, livres, uns em relação aos outros, e não se desenvolvem segundo uma autonomia sem limite: da diferenciação primária dos objetos à formação das estratégias discursivas existe toda uma hierarquia de relações" ${ }^{29}$, o que funciona também em sentido inverso. De todo modo, tudo ocorre sempre no plano discursivo, nunca em uma pré-discursividade que lhe fosse outra e, ao mesmo tempo, determinante. Trata-se para Foucault de destacar a regularidade da prática discursiva que constrói no tempo um discurso, associando diferentes planos de formação discursiva segundo regras que compõem um feixe de relações no tempo. "Definir em sua individualidade singular um sistema de formação é, assim, caracterizar um discurso ou um grupo de enunciados pela regularidade de uma prática" ${ }^{30}$.

27 Foucault, A arqueologia do saber, p. 72; fr. p. 91.

28 Foucault, A arqueologia do saber, p. 74; fr. p. 93.

29 Foucault, A arqueologia do saber, p. 81; fr. p. 101.

30 Foucault, A arqueologia do saber, p. 82; fr. p. 102. 
O segundo ponto, a respeito da especificidade de um período em relação a diferentes discursos, traz ao jogo o princípio crítico da arqueologia.

\section{III - Arqueologia: a síntese de formações discursivas e a síntese de uma episteme}

"Receio que não nos livraremos de Deus, pois ainda cremos na gramática".

(Nietzsche, O crepúsculo dos ídolos).

A certa altura de $A$ arqueologia do saber, Foucault circunscreve seu campo de análise a partir de uma definição mais precisa de um dos termos envolvidos na formação discursiva. $\mathrm{O}$ que lhe interessa particularmente é a função enunciativa, dando forma e conteúdo a um plano de análise distinto da linguística e da análise lógica (embora a eles relacionado). Assim, as unidades efetivamente em jogo em uma análise discursiva de tipo arqueológico são os enunciados. Nesse plano, a regularidade de um feixe é ainda o modo de sua formação, mas da formação de uma série de signos que, a princípio, não se estrutura em um modo fixo, como o de uma gramática. Segundo Foucault, "não há razão para espanto por não se ter podido encontrar para o enunciado critérios estruturais de unidade; é que ele não é em si mesmo uma unidade, mas sim uma função que cruza um domínio de estruturas e de unidades possíveis e que faz com que apareçam, com conteúdos concretos, no tempo e no espaço" ${ }^{\prime 31}$. Nesse plano, portanto, há unidades que são funções que não se estruturam "por si mesmas" segundo alguma regra própria de relação, mas que assumem de certo modo a estrutura de planos diferentes.

A questão é compreender em que plano os enunciados adquirem certa forma específica. "A constância do enunciado, a manutenção de sua identidade através dos acontecimentos singulares das enunciações, seus desdobramentos através da identidade das formas, tudo isso é

31 Foucault, A arqueologia do saber, p. 98; fr. p. 120. 
função do campo de utilização no qual ele se encontra inserido" 32 . É na ordem do campo de utilização, então, que um princípio sintético aparece; ou melhor, reaparece, remetido ao plano do sistema de formação já discutido. Assim, por "discurso" Foucault entende: "conjunto de enunciados que se apoia em um mesmo sistema de formação; é assim [diz Foucault] que poderei falar do discurso clínico, do discurso econômico, do discurso da história natural, do discurso psiquiátrico"33. Porém, permanece aqui a análise ampla da formação discursiva, aquém ainda de uma crítica arqueológica.

Na análise da formação discursiva, "a regularidade dos enunciados é definida pela própria formação discursiva" 34 , de modo que é nesse campo discursivo histórico que uma regularidade se forma, balizando o jogo de diferenciação e dispersão dos enunciados e definindo um campo de positividade. A prática discursiva está aquém da crítica arqueológica no sentido de que suas regras são contingentes na geografia e no tempo. Entretanto, é ainda uma prática discursiva, ou melhor, um discurso, o campo positivo em que se forma um " $a$ priori histórico": "quero designar um a priori que não seria condição de validade para juízos, mas condição de realidade para enunciados" ${ }^{35}$. Embora estejam em jogo as "condições de emergência" dos enunciados, o termo "a priori" refere-se à história dada (daí a materialidade dos enunciados), às coisas "efetivamente ditas". É um tipo específico de história que forma um discurso e há um a priori em cena na medida em que este "define-se como o conjunto das regras que caracterizam uma prática discursiva" ${ }^{36}$. Ou seja, as regras de uma formação discursiva são contingentes na geografia e no tempo por não obedecerem a alguma estrutura que as preceda, que preceda a prática discursiva; mas a prática discursiva passada, em análise, constitui uma positividade cujas regras já estão formadas e podem então ser descritas, inclusive no processo

\footnotetext{
32 Foucault, A arqueologia do saber, p. 118; fr. p.144.

33 Foucault, A arqueologia do saber, p. 122; fr. p. 148.

34 Foucault, A arqueologia do saber, p. 132; fr. p. 161.

35 Foucault, A arqueologia do saber, p. 144; fr. p. 174.

36 Foucault, A arqueologia do saber, p. 145; fr. p. 175.
} 
de emergência de enunciados nessa formação discursiva (arquivo $\left.{ }^{37}\right)$. $O$ processo de emergência do discurso obedece então a uma "regularidade específica".

A dificuldade arqueológica começa a aparecer quando o arquivo em jogo como discurso específico delimita uma descontinuidade na prática discursiva. Se "a arqueologia descreve os discursos como práticas especificadas no elemento do arquivo" ${ }^{\prime 38}$, então ela é uma descrição que precisa dar conta não apenas da unidade sintética de um discurso, o que a regularidade de práticas enunciativas permite entrever, mas da ruptura que distingue uma "atualidade", ainda que ela escape a "nós mesmos": "A análise do arquivo comporta, pois, uma região privilegiada: ao mesmo tempo próxima de nós, mas diferente de nossa atualidade, trata-se da orla do tempo que cerca nosso presente, que o domina e que o indica em sua alteridade; é aquilo que, fora de nós, nos delimita" ${ }^{39}$. Esta delimitação é problemática porque até então um discurso mantinha sua especificidade em função da regularidade enunciativa; outra coisa é compreender não apenas que uma regularidade específica dê lugar a outra, constituindo um arquivo distinto de outro (como a economia política em relação à análise das riquezas), mas sobretudo que a regularidade de um discurso tenha uma relação mais forte do que mera analogia com outros discursos, circunscrevendo uma atualidade. Aqui se localiza propriamente o problema da síntese das diferentes formações discursivas.

\section{1. Regularidade x continuidade / descontinuidade}

O ponto central, parece-me, para caracterizar a arqueologia, talvez não tanto em seus aspectos formais, mas no modo como aparece operando efetivamente em As palavras e as coisas, está no estatuto dos "períodos enunciativos". "Nas confusas unidades chamadas 'épocas',

\footnotetext{
37 "É o sistema geral da formação e da transformação dos enunciados" (Foucault, A arqueologia do saber, p. 148; fr. p. 179).

38 Foucault, A arqueologia do saber, p. 149; fr. p. 180.

${ }^{39}$ Foucault, A arqueologia do saber, p. 148; fr. p. 179-180.
} 
ela faz surgirem, com sua especificidade, 'períodos enunciativos'"'40. Foucault cuida em distinguir esses períodos enunciativos de uma espécie de visão de mundo (Weltanschauung) capaz de descrever algum "espírito de época". É por isso que é preciso deixar bastante claro o ponto central da síntese operada pela arqueologia (das ciências humanas, ao menos), distinta, talvez, desse amplo espaço de uma racionalidade exclusiva. É deste horizonte, sem dúvida, que Foucault pretende tomar distância, quando especifica sua empreitada como aquela que se realiza em uma "região de interpositividade". Não se trata, pois, de totalidade, mas de uma generalidade cujo princípio sintético - esse que amarra positividades em certa configuração epistêmica - está ainda em questão.

O eixo que cruza as positividades em uma região específica (como a Gramática Geral, e História Natural e a Análise das riquezas, todas entrecruzadas em uma episteme clássica) é descrito pela arqueologia em função das regras de formação desses discursos. Ou seja, a regularidade que sustenta diferentes formações discursivas forma o plano em que se pode apreender a "lei de suas comunicações" ${ }^{41}$. Trata-se de "descrever o campo de vetores e de receptividade diferencial (de permeabilidade e de impermeabilidade) que, para o jogo das trocas, foi uma condição de possibilidade histórica" ${ }^{42}$. Vê-se que essa configuração de interpositividade (ou configuração interdiscursiva) guarda em seu núcleo a condição de possibilidade histórica desse "inter", desse espaço comum que torna possíveis essas diferentes positividades ou discursos.

A arqueologia confronta discursos para encontrar a posteriori esse entrecruzamento, essas leis. De partida, havia o confronto (acidental?) de três positividades, como sugere Foucault: "Confrontando a gramática geral, a história natural e a análise das riquezas nos séculos XVII e XVIII, poderíamos..." ${ }^{43}$. É a descrição que faz aparecer uma rede interdiscursiva, que não é "visível” de partida: “Tais redes não

\footnotetext{
40 Foucault, A arqueologia do saber, p. 167; fr. p. 202.

41 Foucault, A arqueologia do saber, p. 182; fr. p. 221.

42 Foucault, A arqueologia do saber, p. 180; fr. p. 220.

43 Foucault, A arqueologia do saber, p. 180; fr. 218.
} 
são, pois, em número previamente definido, só a prova da análise pode mostrar se existe e quais existem (isto é, quais são suscetíveis de serem descritas)" ${ }^{44}$. Há uma experimentação arqueológica sobre alguns discursos que surpreende, quando possível, uma rede interdiscursiva específica, possibilidade cujo critério é a própria descrição. Ao invés de imprimir uma continuidade nos acontecimentos discursivos, como faria a história das ideias, a arqueologia imprime uma regularidade fictícia? - cuja possibilidade está na docilidade dos discursos a essa regularidade reconstituída.

Essa regularidade tem diferentes níveis e recortes, conforme diferentes formações discursivas. Há um "jogo de analogias e de diferenças" que permite à arqueologia comparar discursos tais como aqueles que compõem certa unidade sob o termo "ciências humanas". Mais amplo que essa espécie de unidade é o fundo geral em que ela se localiza como especificidade, cujas dimensões temporais - nascimento e termo - serão discutidos a seguir:

Em outras palavras, a descrição arqueológica dos discursos se desdobra na dimensão de uma história geral; ela procura descobrir todo o domínio das instituições dos processos econômicos, das relações sociais nas quais pode articular-se uma formação discursiva; ela tenta mostrar como a autonomia do discurso e sua especificidade não lhe dão, por isso, um status de pura idealidade e de total independência histórica; o que ela quer revelar é o nível singular em que a história pode dar lugar a tipos definidos de discurso que têm, eles próprios, seu tipo de historicidade e que estão relacionados com todo um conjunto de historicidades diversas ${ }^{45}$.

Desse modo, há um fundo geral no qual se destaca uma interdiscursividade específica, composta por sua vez pela comparação de elementos diversos, dispostos de tal forma que apresentam um jogo específico (regularidade) no nível da formação de regras - o que fornece o campo comum no qual se desenrolam analogias e diferenças.

44 Foucault, A arqueologia do saber, p. 180; fr. 217.

45 Foucault, A arqueologia do saber, p. 185-186; fr. p. 225. 
Assim, há dois níveis sintéticos em questão: o fundo de história geral e a interpositividade discursiva.

Uma coisa é descrever a formação de regras, que organiza o jogo de analogias e diferenças em um discurso (como a História Natural) ou entre alguns discursos (como a História Natural em relação à Gramática Geral e à Análise das riquezas). Aqui, a síntese permanece sendo a regularidade, aquém da oposição entre continuidade e descontinuidade. Porém, para efetivar a descrição crítica da arqueologia, Foucault refere a síntese interdiscursiva, e com ela a síntese de um discurso, a uma espessura temporal: outro estatuto sintético está implicado na dimensão temporal que a arqueologia permitiria entrever para um discurso e, principalmente, para uma rede discursiva específica. Não se questiona com isso que a circunscrição seja específica, no sentido de que a arqueologia não remete a uma Weltanschauung ${ }^{46}$. Ao contrário, questiona-se o que permanece de síntese temporal quando a espécie de unidade interdiscursiva desenha uma continuidade nos limites da transformação que a torna possível e que a encerra - portanto, face à descontinuidade.

Foucault é muito cuidadoso ao diferenciar arqueologia e história das ideias, recusando todo tipo de referência continuísta na análise histórica (o que, inversamente, permite recusar a criação como algo que espirra como um salto de gênio de água correntes). Então, como descrever arqueologicamente a mudança? A exposição do método parece revelar uma espessura que, no limite, é arbítrio do olhar de um arqueólogo possível, sobrepondo-se às análises do jogo entre analogias e diferenças cuja regularidade uma genealogia (ou um nominalismo em história) poderá descrever como acontecimento na ordem do saber. Por outro lado, a arqueologia, esse "discurso sobre discursos", é "fazer as diferenças; constituí-las como objeto, analisá-las e definir seu conceito" ${ }^{\prime 7}$. Assim, o que efetivamente caracteriza a arqueologia, ou o procedimento essencial de sua descrição, está concentrado, a meu ver,

${ }^{46}$ Esse cuidado metodológico não poderia manter-se nos trabalhos posteriores, em que Foucault formula a noção de "ontologia histórica", pois neste caso há referência a um modo de ser específico, que imprime uma espessura incontornável à forma de reflexividade que lhe corresponde.

${ }^{47}$ Foucault, A arqueologia do saber, p. 230; fr. p. 278-279. 
na seção $V$. A Mudanças e as Transformações do capítulo IV. A Descrição Arqueológica do livro A Arqueologia do Saber.

Em primeiro lugar, Foucault trata da "aparente sincronia das formações discursivas" (A). A temporalidade de diferentes formações discursivas não implica uma ordem sucessiva de enunciados, mas distingue uma sucessão de enunciados próprios de cada uma dessas formações em sua singularidade histórica, em função das regras de formação deste conjunto. Essas regras de formação, "em seu interior", têm distintas posições temporais e de subordinação. Portanto, ainda que a arqueologia distinga-se de um modelo linear ou de um modelo lógico de simultaneidades, a rede de acontecimentos que ela destaca no jogo de enunciados é um entrecruzamento específico, um "sistema de positividade". A questão é justamente o recorte que dá espessura histórica a esse sistema.

Espessura mais breve, certamente, que aquela que a história procurava estabelecer tradicionalmente, estendendo-a ao máximo, à sua continuidade mais geral. É por isso que, ao contrário daquela, a arqueologia é marcada pelo signo da descontinuidade, das rupturas (B). A força dessa marca deixa em segundo plano, talvez, o problema da breve continuidade cuja espessura designa o espaço temporal em que se desenrola um sistema de positividade específico. Assim, se é verdade que a arqueologia "procede inversamente; procura soltar todos os fios ligados pela paciência dos historiadores; multiplica as diferenças, baralha as linhas de comunicação e se esforça para tornar as passagens mais difíceis" 48 , é verdade também que ela não solta todos os fios dos acontecimentos em uma verdadeira dispersão aberta à ficção do olhar que estabelece sentido surpreendendo relações diversas e sempre exteriores às singularidades em jogo. Mantém-se pequenas linhas apoiadas em uma regularidade que o arqueólogo poderia destacar a posteriori, mas que são internas ao sistema de positividade, aos discursos entrelaçados. Trata-se então, para o arqueólogo, de diferenciar as diferenças - ou seja, trata-se de negar as relações. Porém, nem sempre alcançando o limite do simples, do singular.

${ }^{48}$ Foucault, p. 191; fr. p. 231. 
Segundo Foucault, diversos planos de acontecimentos ocorrem "na unidade profunda do discurso" ${ }^{49}$, ou seja, há diferenças que participam "de uma única positividade" 50 . Outro nível estabelece, contudo, "a substituição de uma formação discursiva por outra (ou do aparecimento e do desaparecimento puro e simples da positividade)"51. É claro que está nesse acontecimento maior, que delimita a idade de uma formação discursiva, o problema do primeiro nível sintético, referente à história geral. Há também o nível sintético que coordena diferentes formações discursivas nesse mesmo espaço.

O vocabulário arqueológico substitui então "mudança" por "transformação". "Em vez de invocar a força viva da mudança (como se esta fosse seu próprio princípio), ou lhe procurar as causas (como se nunca passasse de puro e simples efeito), a arqueologia tenta estabelecer o sistema das transformações em que consiste a "mudança"; tenta elaborar essa noção vazia e abstrata para dar-lhe o status analisável da transformação" ${ }^{\prime 2}$. Porém, na mesma medida em que esta noção de transformação sobe ao palco em substituição daquela outra, "vazia e abstrata", de mudança, ela só existe em relação a esta última, como a marca de uma diferença entre continuidades relativas, entre singularidades históricas cuja identidade é revelada pela arqueologia em função de regularidades específicas. Há regularidade entre descontinuidades, mudanças entre transformações, formando espaços discursivos positivos. Portanto, Foucault responde - e insiste nisso - àqueles que se prendem à imaginação do movimento, do fluxo, da evolução ${ }^{53}$, mas seria preciso responder, ao contrário, à sutil permanência do fluxo na forma de um a priori histórico ${ }^{54}$.

49 Foucault, A arqueologia do saber, p. 170

${ }^{50}$ Foucault, $A$ arqueologia do saber, p. 173; fr. p. 233.

51 Foucault, $A$ arqueologia do saber, p. 193; fr. p. 233.

52 Foucault, A arqueologia do saber, p. 194; fr. p. 235.

53 "Compreende-se que certas mentes, ligadas a todas as velhas metáforas pelas quais, durante um século e meio, concebeuse a história (movimento, fluxo, evolução) vejam aí tão-somente a negação da história e a afirmação frustrada da descontinuidade" (Foucault, A arqueologia do saber, p. 194; fr. p. 235).

${ }^{54}$ Não se trata aqui de recusar o feixe, o fluxo, a regularidade que dá corpo às ciências, às formações discursivas e às coisas, mas o estatuto do vínculo entre elementos que recorta uma formação discursiva específica na história, ou de algumas formações, cujo sentido arqueológico próprio é mais profundo que uma circunscrição genealógica. 
É verdade que a força desse nível sintético (temporal / história geral) - e talvez também o outro nível sintético (inter-positividades) - é minimizado por Foucault no livro de 1969. Há então certas permanências que não obstruem as transformações, embora estas não possam ser determinadas por um aspecto ou outro das formações discursivas. Por isso é possível questionar "como pode haver permanências ou repetições, longos encadeamentos ou curvas que traspõem o tempo?" "55. Se na explicitação metodológica o foco do arqueólogo é a descontinuidade, a transformação ela mesma, e não alguma permanência, talvez seja porque a possibilidade dessa ênfase esteja na análise bastante vinculada às positividades descritas, no caso de $A$ arqueologia do saber. Não parece possível esquivar-se dessa mesma questão das semi-permanências, atraindo a atenção para as descontinuidades (contra os continuístas engajados em uma história racional), considerando a força da discussão a respeito da diferença entre "ser do homem" e "ser da linguagem" como característica da época moderna, em contraposição à transparência entre essas esferas na era da Representação ${ }^{56}$.

A continuidade, segundo Foucault, não é oposta à descontinuidade: trata-se de "fazer atuar o contínuo e o descontinuo um contra o outro" 57 . É por isso que a continuidade é relativa à descontinuidade. Afinal, "o contínuo é formado segundo as mesmas condições e conforme as mesmas regras que a dispersão" ${ }^{\prime 58}$. Nesse jogo, a força quase estrutural que se podia ler em As palavras e as coisas dá lugar a uma análise mais plástica de transformações diversas em $A$ arqueologia do saber. Portanto, tudo aquilo que se pode encontrar em uma análise genealógica ou "nominalista" encontra-se em jogo na exposição de 1969; ao mesmo tempo em que o caráter sintético próprio da arqueologia como princípio crítico permanece e a justificativa de sua necessidade escapa à exposição de Foucault. Ou seja, se "existem entre as diferentes rupturas arqueológicas importantes defasagens - e, às vezes, mesmo entre formações discursivas muito próximas e ligadas por numerosas

\footnotetext{
55 Foucault, A arqueologia do saber, p. 195; fr. p. 236.

56 Cf. Foucault, As palavras e as coisas, particularmente os capítulo IX e X.

57 Foucault, A arqueologia do saber, p, 190; fr. p. 237.

58 Foucault, A arqueologia do saber, p. 190; fr. p. 237.
} 
relações" 59 , para que manter a noção de arqueologia? O nível sintético que vincula positividades distintas já não se mostra tão específico, e a síntese de uma regularidade no tempo dissolve-se, então, em acontecimento singular. Sem a força de uma episteme clássica em sua diferença com a episteme moderna, tal como se lê em As palavras e as coisas, não parece restar nada de próprio ao empreendimento arqueológico.

Foucault procura recusar a perspectiva da história das ideias, por um lado, e do estruturalismo, por outro. A arqueologia seria outra coisa; e ela é, de fato, outra coisa. Porém, é preciso reconhecê-la, ao que parece, na radicalidade da descontinuidade que ela coloca em jogo. Jogo no qual a continuidade não será diferente da descrição $a$ posteriori de uma regularidade possível, como fará a genealogia - mas sem o peso constrangedor do a priori, da episteme, do antropologismo, ou mesmo da época.

A arqueologia desarticula a sincronia dos cortes, como teria desfeita a unidade abstrata da mudança e do acontecimento. A época não é nem sua unidade de base, nem seu horizonte, nem seu objeto; se fala sobre ela, é sempre a propósito de práticas discursivas determinadas e como resultado de suas análises. A época clássica, que foi frequentemente mencionada nas análises arqueológicas, não é uma figura temporal que impõe sua unidade e sua forma vazia a todos os discursos; é o nome que se pode dar a um emaranhado de continuidades e descontinuidades, de modificações internas às positividades, de formações discursivas que aparecem e desaparecem. Da mesma forma, a ruptura não é, para a arqueologia, o ponto de apoio de suas análises, o limite que ela mostra de longe, sem poder determina-lo nem dar-lhe uma especificidade: a ruptura é o nome dado às transformações que se referem ao regime geral de uma ou várias formações discursivas ${ }^{60}$.

Eis que se pode reencontrar aí, no uso plástico dos termos "época" e "ruptura", um "regime geral" que diz respeito a uma ou várias formações discursivas, cujo vínculo específico permanece incerto. Mas se, de todo modo, a arqueologia requer uma circunscrição como essa,

59 Foucault, A arqueologia do saber, p. 197; fr. p. 238.

${ }^{60}$ Foucault, A arqueologia do saber, p. 198; fr. p. 239. 
dada pela marca da ruptura ou da época, por que manter a designação de uma fronteira crítica - sob o título de arqueologia - procurando minimizá-la, descobrindo nela uma porosidade que, no limite, a desfaz? Radicalizar a descontinuidade não impede a descrição do jogo, da regularidade discursiva ou interdiscursiva; apenas a retira da clausura de uma semi-continuidade com fronteiras definidas por rupturas.

\section{IV - Por que "arqueologia"?}

Nesse sentido, por que designar, como Alain de Libera, a genealogia de um conceito por "Arqueologia do sujeito"? Além da dificuldade em definir a "arqueologia" como método de análise, esse trabalho de fôlego não poderia fazê-lo nos termos de Foucault, já que "sujeito" não é uma formação discursiva ${ }^{61}$. Se a arqueologia pretende, de todo modo, ser a descrição das regras de formação de um discurso, como pensar uma arqueologia do sujeito? Aliás, não é justamente como elemento de uma formação discursiva específica que esse termo adquire sentido positivo? Uma arqueologia parece supor a descrição do sistema discursivo de enunciação (corpo) em que um enunciado-coisa como "sujeito" é possível.

“O problema é que ninguém está de acordo sobre o fim da Idade Média, e não basta que seu tempo seja considerado passado para que se tenha dele saído" ${ }^{\prime 2}$. Essa fórmula faz ver a fronteira incerta de uma época que balança as noções de nascimento e morte - não tanto a continuidade tradicional de uma história racional. A porosidade de uma fronteira arqueológica torna equívoca a própria singularidade histórica quando situada em termos a um só tempo específicos e gerais, tal

61 "Sujeito" pode ser uma forma discursiva, como diz Alain de Libera, o que não significa "formação discursiva" em sentido foucaultiano. Quando Alain de Libera apresenta sua Arqueologia do sujeito - "Nem história da subjetividade nem genealogia(s) do sujeito, mas no espaço definido por essa dupla negação, o trabalho de uma forma discursiva, a forma 'sujeito', seus teoremas, seus princípios, seus conceitos, seus problemas, os diversos conteúdos que ela sucessivamente, às vezes contraditoriamente, obteve nas fronteiras da metafísica, da lógica e da filosofia do espírito: tal é o propósito" (Libera, Archéologie du sujet I, p. 12) - ele situa a questão no nível da linguagem, mas não no nível de um saber específico.

${ }^{62}$ Libera, Où va la philosophie médiévale?, p. 6. 
como o de "época". Ela não coloca apenas em xeque a continuidade que atravessa rupturas, mas a semi-continuidade que dá sentido a estas. Ainda que Alain de Libera encontre "outra" ou a "nossa" Idade Média na "diversidade rebelde" ${ }^{63}$ que a dispersa na pluralidade de distintas "Idades Médias", ele não tarda a somar a ela a noção de "estrutura", que recompõe a dispersão por meio de "leis e formas que se impõem ao sujeito malgrado ele próprio" ${ }^{64}$. O jogo arqueológico da continuidade e da descontinuidade se refaz em outros termos, os de diversidade e estrutura, no percurso de Alain de Libera: "No final dos anos 1960, parecia ter chegado o momento para um jovem medievalista revisitar a Idade Média com as ferramentas conceituais de sua geração, confrontar a diversidade, fosse ela ou não rebelde, e a estrutura, fosse ela geral ou individualizada" 65 .

Munido de tais ferramentas, Alain de Libera se volta ao problema da história, da periodização, de maneira foucaultiana: "A filosofia medieval pode apenas se abrir em um acontecimento para a filosofia" 66 , ou seja, como acontecimento específico na ordem do saber, uma espécie de formação discursiva - diferentemente de quando a questão se coloca em relação ao "sujeito". É, aliás, como condição de uma forma de pensamento que Alain de Libera toma a sério, e para si, o termo kantiano de Foucault: "Em todo caso, é ele [Foucault] que, polemizando com George Steiner, retomou a ideia kantiana de uma philosophische Archäologie, dito de outro modo, em sua interpretação, como a história do que torna necessária uma certa forma de pensamento" ${ }^{67}$. E talvez não seja tão estranha - como aliás ele mesmo mostra - a proximidade entre Gueroult et Foucault: "Até que ponto podemos seguir ao mesmo tempo Gueroult e Foucault conceitualmente e narrativamente?"68.

\footnotetext{
63 Alain de Libera reporta-se aqui à frase de Vignaux: "0 historiador que recebeu uma formação filosófica deve temer unificar demais, sistematizar; é preciso que ele deixe ver a diversidade rebelde" (P. Vignaux, Philosophie au Moyen Âge, Pari, Vrin, 3 éd. 2004, p. 94-95, apud Libera, Où va la philosophie médiévale?, nota 13).

${ }^{64}$ Gueroult, Leçon inaugurale au Collège de France, p. 23, apud Libera, Où va la philosophie médiévale?, nota 15.

65 Libera, Où va la philosophie médiévale?, p. 10.

${ }^{66}$ A. de Libera, Où va la philosophie médiévale?, p. 17.

${ }^{67}$ A. de Libera, Où va la philosophie médiévale?, p. 22.

${ }^{68}$ A. de Libera, Où va la philosophie médiévale?, p. 23.
} 
Mobilizando também Collingwood, Alain de Libera procura estabelecer o sentido da "estrutura" em jogo em uma arqueologia. Porém, chega-se assim a um referente aberto, a um complexo sem fronteiras - não apenas porosas, mas incertas como em qualquer genealogia, ao contrário das epistemes arqueologicamente descritas. "A arqueologia filosófica procura fazer seus não apenas os vocábulos e as questões de um filósofo, mas, além disso, sua organização, sua 'estrutura' - a palavra é de Collingwood"69. Essa organização seria o plano de um "complexo questões-respostas" (CQR) que permite pensar um pensamento passado, "re-efetuar" um acontecimento segundo suas condições de existência.

Assim como na arqueologia de Foucault as transformações - e por simetria, inversamente, os acontecimentos - afetam conceitos e relações (e não homens, como notou Canguilhem), para Alain de Libera "para além de atores, indivíduos, grupos, classes e 'forças em conflito', intervêm a partir deles mesmos, a título de atuantes (actants), os princípios, as distinções, os esquemas ou as estruturas conceituais e argumentativas"70. Isso significa que sua arqueologia toma a sério a dimensão discursiva como objeto de descrição e análise. Mas, nesse sentido, quando ele afirma que "os acontecimentos eles próprios têm uma duração"71, a temporalidade do acontecimento fecha-se sobre si, sem remeter a um nível sintético que pudesse entrecruzar diferentes acontecimentos ou formações discursivas segundo um a priori histórico comum. Neste caso, a temporalidade fecha-se como episteme, mais ampla e fundamental que a espessura de um acontecimento. Se for verdade que um tal quadro sintético caracteriza efetivamente a arqueologia (ao menos aquela de Foucault), seria o caso de perguntar-se em que medida o termo não carrega consigo o perigo de um quase-transcendental para o qual um acontecimento perde sua singularidade. Peso este que a investigação de Alain de Libera sobre o sujeito não parece ter efetivamente, ou pelo menos não precisa ter.

\footnotetext{
69 A. de Libera Où va la philosophie médiévale?, p. 23.

70 A. de Libera, Où va la philosophie médiévale?, p. 28.

71 A. de Libera, Où va la philosophie médiévale?, p. 28.
} 
Teria o quadrilátero medieval de Alain de Libera o mesmo estatuto do quadrilátero da episteme clássica em sua analogia e diferença com o quadrilátero moderno apresentados por Foucault ${ }^{72}$ ? Em quatro questões interligadas, Alain de Libera apresenta a "estrutura" ou "esquema teórico" medieval para a questão do sujeito. Este acontecimento singular é o sentido do quadrilátero, diferentemente dos dois quadros que compreendem para Foucault o sentido geral da linguagem na época clássica e na época moderna, o que torna particular uma determinada episteme. Naquele caso, não parece estar em jogo, efetivamente, um a priori histórico, embora Alain de Libera apresente a questão que coordena seu quadrilátero interrogativo desse modo: "Em sua inter-implicação, as quatro [questões] podem servir de formulário para questionar 'a' questão do sujeito do pensamento, e identificar seu 'a priori histórico'"'73.

Seria possível argumentar que Foucault escreve, ele mesmo, em 1982, não apenas uma genealogia do sujeito, uma hermenêutica do sujeito, mas uma arqueologia. Porém, quando ele empreende uma investigação acerca do "sujeito", o que está em jogo enquanto arquivo é o "saber científico do sujeito". Nessa medida, há um aspecto metodológico que é arqueológico. Diz Foucault "Dedico-me, antes, a uma história da ciência que, em certa medida, é uma história regressiva que procura descobrir as práticas discursivas institucionais e sociais a partir das quais essas ciências irromperam. Tratar-se-ia aqui de uma história arqueológica"74. Mas esse é um aspecto da grande genealogia do sujeito moderno que se encontra desenvolvida no curso de dois anos depois. Isso é sugerido inclusive pela nota que os editores acrescentam a essa passagem, na qual se lê Foucault afirmando que se trata agora, todavia, de "um outro método", "que consistia em uma maneira de considerar menos o conteúdo da ciência que sua própria existência"75. Considera-se então a emergência histórica da própria prática discursiva, a emergência da formação discursiva, e não a forma geral que

\footnotetext{
72 Foucault, As palavras e as coisas, capítulo IV, seções III, IV, V, VI e capítulo IX, seções III, IV, V e VI, respectivamente.

73 Libera, Où va la philosophie médiévale?, p. 35.

74 Foucault, Verdade e Subjetividade, p. 5; fr, p. 36 (Berkeley).

75 Foucault, L'origine de l'herméneutique du soi, p. 56, nota 11.
} 
uma formação - ou várias, em uma interdiscursividade - permitiria circunscrever. Ora, não é por acaso que, no curso de 1982, trata-se de uma hermenêutica, não de uma arqueologia do sujeito.

Em suma, duvidando do sentido que haveria em elaborar hoje a uma "arqueologia", ou mesmo da possibilidade de compreender a discussão de Alain de Libera sobre o sujeito como uma arqueologia, este artigo é uma espécie de propedêutica metodológica a um trabalho futuro. No que diz respeito à discussão metodológica que se impôs pela leitura de Foucault e de Alain de Libera, a noção de redes ou de "história das redes" parece mais operatória, por evitar a inércia de uma espessura que a arqueologia carrega e, também, por permitir que se estabeleça como fio condutor noções múltiplas e dispersas como, por exemplo, a de "sujeito".

\section{Referências}

CANGUILHEM, G. «Mort de l'homme ou épuisement du cogito? », Critique, $\mathrm{n}^{\circ}$ 242, juil. 1967.

FOUCAULT, M. Verdade e subjectividade (Howison Lectures). Revista de Comunicação e linguagem, n. 19. Lisboa: Edições Cosmos, 1993. p. 203-23.

FOUCAULT, M. Les mots et les choses :Une archéologie des sciences humaines (1966), Paris : Gallimard, 2005. [As palavras e as coisas. Trad. Salma Tannus Muchail, São Paulo: Martins Fontes, 2002].

FOUCAULT, M. L'Archéologie du savoir (1969), Paris: Gallimard, 2008. [FOUCAULT, M. A Arqueologia do saber. 7. ed. Rio de Janeiro: Forense Universitária, 2008].

FOUCAULT, L'origine de l'herméneutique de soi, Conférences prononcées à Dartmouth College, 1980. Paris: Vrin, 2013. (collection "philosophie du présent"). HUME, D. Tratado da Natureza Humana: uma tentativa de introduzir o método experimental de raciocínio nos assuntos morais. Trad. Débora Danowski. São Paulo: Editora UNESP/Imprensa Oficial do Estado, 2001. 
LATOUR, B. Jamais fomos modernos: ensaio de antropologia simétrica. Trad. Carlos Irineu da Costa. São Paulo: Ed. 34, 1994.

LEBRUN, G. David Hume dans l'album de famille husserlien. Revista Manuscrito, v. 5, n. 2, abr. 1982.

LIBERA, A. Archéologie du sujet I: Naissance du sujet. Paris: VRIN, 2007.

LIBERA, A. De Où v ala philosophie médiévale? Collège de France, Paris, n. 244, 2014. (Coll. "Leçons inaugurales du Collège de France").

Recebido: 20/01/2019

Received: 01/20/2019

Aprovado: 22/02/2019

Approved: 02/22/2019 